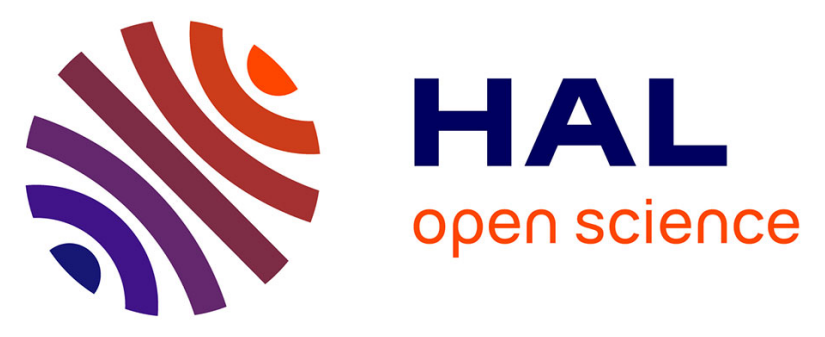

\title{
Sound velocities and density measurements of solid hcp-Fe and hcp-Fe-Si (9 wt.\%) alloy at high pressure: Constraints on the Si abundance in the Earth's inner core
}

Daniele Antonangeli, Guillaume Morard, Luigi Paolasini, Gaston Garbarino, Caitlin A. Murphy, Eric Edmund, Frédéric Decremps, Guillaume Fiquet, Alexei Bosak, Mohamed Mezouar, et al.

\section{To cite this version:}

Daniele Antonangeli, Guillaume Morard, Luigi Paolasini, Gaston Garbarino, Caitlin A. Murphy, et al.. Sound velocities and density measurements of solid hcp-Fe and hcp-Fe-Si (9 wt.\%) alloy at high pressure: Constraints on the Si abundance in the Earth's inner core. Earth and Planetary Science Letters, 2018, 482, pp.446-453. 10.1016/j.epsl.2017.11.043 . hal-01656993

\section{HAL Id: hal-01656993 https://hal.sorbonne-universite.fr/hal-01656993}

Submitted on 6 Dec 2017

HAL is a multi-disciplinary open access archive for the deposit and dissemination of scientific research documents, whether they are published or not. The documents may come from teaching and research institutions in France or abroad, or from public or private research centers.
L'archive ouverte pluridisciplinaire HAL, est destinée au dépôt et à la diffusion de documents scientifiques de niveau recherche, publiés ou non, émanant des établissements d'enseignement et de recherche français ou étrangers, des laboratoires publics ou privés. 
Sound velocities and density measurements of solid hcp-Fe and hcp-Fe-Si(9wt.\%) alloy

2 at high pressure: Constraints on the Si abundance in the Earth's inner core

3

4 Daniele Antonangeli ${ }^{1, *}$, Guillaume Morard ${ }^{1}$, Luigi Paolasini ${ }^{2}$, Gaston Garbarino ${ }^{2}$, Caitlin A.

5 Murphy $^{3}$, Eric Edmund ${ }^{1}$, Frederic Decremps ${ }^{1}$, Guillaume Fiquet ${ }^{1}$, Alexei Bosak ${ }^{2}$, Mohamed 6 Mezouar $^{2}$, Yingwei Fei ${ }^{3}$

7

$8{ }^{1}$ Institut de Minéralogie, de Physique des Matériaux, et de Cosmochimie (IMPMC), UMR

9 CNRS 7590, Sorbonne Universités - UPMC, Muséum National d'Histoire Naturelle, IRD UR 206, 75252 Paris, France.

112 European Synchrotron Radiation Facility, BP 220, 38043 Grenoble Cedex, France.

$12{ }^{3}$ Geophysical Laboratory, Carnegie Institution of Washington, Washington DC 20015, USA 
We carried out sound velocity and density measurements on solid hcp-Fe and an hcpFe-Si alloy with 9 wt.\% $\mathrm{Si}$ at $300 \mathrm{~K}$ up to $\sim 170$ and $\sim 140 \mathrm{GPa}$, respectively. The results allow us to assess the density $(\rho)$ dependence of the compressional sound velocity $\left(\mathrm{V}_{\mathrm{P}}\right)$ and of

20 the shear sound velocity $\left(V_{S}\right)$ for pure Fe and the Fe-Si alloy. The established $V_{P}-\rho$ and $V_{S}-\rho$ 21 relations are used to address the effect of $\mathrm{Si}$ on the velocities in the Fe-FeSi system in the 22 range of Si concentrations 0 to $9 \mathrm{wt} . \%$ applicable to the Earth's core. Assuming an ideal linear 23 mixing model, velocities vary with respect to those of pure $\mathrm{Fe}$ by $\sim+80 \mathrm{~m} / \mathrm{s}$ for $\mathrm{V}_{\mathrm{P}}$ and $\sim-80$ $24 \mathrm{~m} / \mathrm{s}$ for $\mathrm{V}_{\mathrm{S}}$ for each wt.\% of $\mathrm{Si}$ at the inner core density of $13000 \mathrm{~kg} / \mathrm{m}^{3}$. The possible 25 presence of $\mathrm{Si}$ in the inner core and the quantification of its amount strongly depend on 26 anharmonic effects at high temperature and on actual core temperature.

28 Keywords: seismic wave velocities; iron; iron-silicon alloys; high pressure; high temperature; Earth's inner core 
The physical properties of iron and iron alloys at high pressure are crucial to refine the chemical composition and dynamics of the Earth's core. In this respect, density ( $\rho)$, compressional-wave $\left(\mathrm{V}_{\mathrm{P}}\right)$ and shear-wave $\left(\mathrm{V}_{\mathrm{S}}\right)$ sound velocities are of particular importance, as those parameters can be directly compared to seismological observations. Over the last twenty years, a great effort has been devoted to the development of experiments capable of probing sound velocity of metallic samples at high pressure, with a specific focus on iron (see Antonangeli and Ohtani [2015] for a recent review). Ab initio calculations have been extensively applied as well to assess material's properties at core pressures and temperatures [e.g. Vočadlo et al., 2009; Sha and Cohen, 2010; Martorell et al., 2013]. Yet, a consensus has not been reached, not only concerning the absolute values of velocities of solid iron at inner core conditions, but also the dependence of velocities upon pressure and temperature.

Since the seminal work of Birch [1952] it has been well established that light elements are alloyed to iron in the Earth's core to account for the density difference between pure Fe and seismological observations (e.g. model PREM by Dziewonski and Anderson [1981]). For the solid inner core, many recent experimental studies suggest silicon as one of the major candidates, based on its physical properties (density and sound velocity) and/or affinity for the metallic phase during Earth's differentiation [e.g. Lin et al., 2003; Badro et al., 2007; Antonangeli et al., 2010; Mao et al. 2012; Siebert et al., 2013; Fischer et al., 2015; Tateno et al., 2015]. However, different works propose different amount of Si alloyed to Fe in the inner core, ranging from 2wt.\% [Badro et al., 2007; Antonangeli et al., 2010] up to 8\% [Mao et al. 2012; Fischer et al., 2015]. One of the causes for such a discrepancy is the large pressure

53 and temperature extrapolation necessary to compare experimental results with inner core 54 seismological models. For instance, results based on linear extrapolations of $\mathrm{V}_{\mathrm{P}-} \rho$ relation argued for about $2 \mathrm{wt} \% \mathrm{Si}$ alloyed to Fe in the inner core [Badro et al., 2007; Antonangeli et 
al., 2010], while a model using a power law for the $\mathrm{V}_{\mathrm{P}}-\rho$ extrapolation proposed $8 \mathrm{wt} \% \mathrm{Si}$ [Mao et al. 2012]. In contrast with the bulk of the experimental results, a very recent computational work on silicon alloys at inner core conditions [Martorell et al., 2016] suggested that both the P-wave and the S-wave velocities of any hep-Fe-Si alloy would be too high to match the seismically observed values at inner-core density.

To shed light on this ongoing debate, we carried out sound velocity and density measurements on pure Fe and a Fe-Si alloy with 9 wt.\% $\mathrm{Si}$ in the hexagonal close-packed structure (hcp) from $\sim 40 \mathrm{GPa}$ up to $\sim 170 \mathrm{GPa}$, using inelastic $\mathrm{x}$-ray scattering (IXS) and $\mathrm{x}$-ray diffraction (XRD). IXS allows a clear identification of longitudinal aggregate excitations in polycrystalline samples [Fiquet et al., 2001, 2009; Antonangeli et al., 2004, 2010, 2012, 2015; Badro et al., 2007; Mao et al., 2012; Ohtani et al., 2013] and the derivation of $\mathrm{V}_{\mathrm{P}}$ from a sine fit of the phonon dispersion. Combining the measured $V_{P}$ with the bulk modulus derived from the equation of state, $\mathrm{V}_{\mathrm{S}}$ can be determined as well, while the density is directly obtained from the collected diffraction patterns. In this study, we aim to establish precise relations between velocities (both $\mathrm{V}_{\mathrm{P}}$ and $\mathrm{V}_{\mathrm{S}}$ ) and density for $\mathrm{Fe}$ and a representative $\mathrm{Fe}-\mathrm{Si}$ alloy with 9 wt.\% Si over a wide pressure range at room temperature. The results will provide a benchmark for calculations and will serve as reference for further studies of increased compositional complexity or addressing the temperature effects on the velocities.

\section{Materials and Methods}

Starting materials consisted in commercially available polycrystalline samples of Fe (99.998\%, Alpha Aesar) and a Fe-Si alloy with 9 wt.\% Si (Goodfellow, hereafter Fe-Si9). The same Fe-Si alloy was used in previous study of equation of state, with an average Si content 
IXS and XRD measurements have been carried out at the European Synchrotron Radiation facility (ESRF) at ID28 and ID27 beamlines, respectively. IXS measurements have been performed on polycrystalline specimens compressed in a diamond anvil cell (DAC) using the $\operatorname{Si}(9,9,9)$ instrument configuration, which yields an overall energy resolution of 3 meV full width half maximum (FWHM). Absolute energies have been calibrated prior to the experiment comparing IXS diamond phonon dispersion with that obtained by inelastic neutron and Raman scattering. Specific to this experiment, we double-checked the energy calibration by comparing the sound velocity measured by IXS on iron powders at ambient conditions with the Voigt-Reuss-Hill average of ultrasonic determination on single crystal [Guinan and Beshers, 1968]. We also calibrated the scattering angle at the small working values of our IXS measurements by collection of diffraction from a silver behenate standard. Optics in Kirkpatrick-Baez configuration allowed focusing the x-ray beam at sample position at $30 \times 70 \mu \mathrm{m}^{2}$ (horizontal $\mathrm{x}$ vertical, FWHM) or down to $12 \times 7 \mu \mathrm{m}^{2}$ (horizontal $\mathrm{x}$ vertical, FWHM) depending upon DAC configuration. Momentum resolution was set by slits in front of the analyzers to $0.28 \mathrm{~nm}^{-1}$ and to $0.84 \mathrm{~nm}^{-1}$, in the scattering plane and perpendicular to it. A vacuum chamber was used to minimize the quasi-elastic scattering contribution from air. Good-statistic data have been obtained with typical integration time of $\sim 300$ s per point for Fe, and $\sim 500-600$ s per point for Fe-Si9.

Pressures were generated by symmetric type, MAO DAC, using composite Re/c-BN gaskets, with either $150 / 300 \mu \mathrm{m}$ beveled anvils, or $40 / 100 / 250 \mu \mathrm{m}$ beveled anvils prepared by focus ion beam (FIB) milling technique [Fei et al., 2016]. Diamonds were pre-aligned and oriented to select the fastest transverse acoustic phonon of the diamond in the scattering plane and to minimize its intensity. The focused beam of $12 \times 7 \mu \mathrm{m}^{2}$ FWHM at sample position granted collection of clean spectra on specimens down to $\sim 35 \mu \mathrm{m}$ in diameter. Such a small beam also permitted to probe phonons across moderate pressure gradients (as determined 
105 from the fine diffraction mesh, see below), while the composite gasket ensured relatively thick samples ( 8 to $12 \mu \mathrm{m}$ at the highest pressure), and hence proper IXS signal, averaged over a reasonably large number of grains. Pressure was increased off line by monitoring the

108 Raman spectra at the tip of the diamonds, and more precisely measured by the x-ray 109 diffraction according to known samples equation of state. Specifically we used a third-order 110 Birch-Murnaghan formalism, with $\mathrm{V}_{0}=22.47 \AA^{3} /$ unit cell [Dewaele et al. 2006], $\mathrm{K}_{0}=155$ $111 \mathrm{GPa}$ and $\mathrm{K}^{\prime}=5.37$ [Sakai et al., 2014] for hcp-Fe and $\mathrm{V}_{0}=23.50 \AA^{3} /$ unit cell, $\mathrm{K}_{0}=129 \mathrm{GPa}$ 112 and $\mathrm{K}^{\prime}=5.24$ for hcp-Fe-Si9 [Fei, 2017].

At each investigated pressure point, we mapped the aggregate longitudinal acoustic 114 phonon dispersion throughout the entire first Brillouin zone collecting 6 to 9 spectra in the 3$11512.5 \mathrm{~nm}^{-1}$ range. The energy positions of the phonons were extracted by fitting a set of 116 Lorentzian functions convolved with the experimental resolution function to the IXS spectra. 117 Figure 1 shows an example of the collected IXS spectra and the fitted result. We derived $V_{P}$ 118 from a sine fit to the phonon dispersion [Antonangeli et al., 2004] (Figure 1), with error bars 119 between \pm 1 and $\pm 3 \%$ for Fe and between \pm 2 and $\pm 4 \%$ for Fe-Si9. The errors account for 120 statistical errors, finite energy and momentum resolution, as well as deviation from ideal 121 random orientation of the polycrystalline samples. Combining the measured $V_{P}$ with bulk 122 modulus from the equation of state (the difference between isothermal and adiabatic bulk 123 modulus at $300 \mathrm{~K}$ is negligible), we also derived $\mathrm{V}_{\mathrm{S}}$ [Antonangeli et al., 2004], with 124 uncertainties, obtained by propagating uncertainties on $V_{P}$ and on $K$ (the contribution from 125 uncertainties on density was observed to be negligible), between \pm 5 and $\pm 6 \%$ for pure-Fe, and 126 between \pm 8 and $\pm 10 \%$ for $\mathrm{Fe}$-Si9 (assuming different equation of state leads to small effects on $\mathrm{V}_{\mathrm{S}}$ well within reported error bars). For both samples, we collected angle dispersive 2D diffraction patterns at each 129 investigated pressure point, with a monochromatic wavelength of $0.3738 \AA$ (iodine $\mathrm{K}$ edge). 
130 This allowed for clear structure determination and direct measurements of samples' density.

131 Taking advantage of the $3 \times 3 \mu \mathrm{m}^{2}$ beam, we mapped the entire sample area, monitoring 132 pressure gradients across the sample chamber. Diffraction data are also used to detect any 133 developed texture. Examples of collected diffraction patterns are shown in Figure 2 and 134 Figure 3. The diffraction patterns of the compressed hcp-Fe (Figure 2) show rather smooth 135 rings, indicating the small sizes of the diffracting crystallites (average size $\sim 25 \mathrm{~nm}$ at 167 $136 \mathrm{GPa}$ ) and the good orientation averaging (only 100 reflection shows some variation in 137 intensity with the azimuthal angle). Two-dimensional detector images caked into rectilinear 138 projection show negligible dependence of the $\mathrm{d}$ spacing on the azimuthal angle around $2 \theta=0$ 139 direction (Figure 2), and hence a negligible deviatoric stress [Wenk et al., 2006]. Furthermore, 140 the (002) reflection, although weak, is still visible up to the highest attained pressure, further 141 highlighting the marginal preferential orientation. Such observations support the overall 142 validity of the random orientation approximation, critical to the analysis and interpretation of 143 the IXS results [Antonangeli et al., 2004; Bosak et al., 2007;2016]. The diffraction patterns 144 collected for the Fe-Si9 alloy (Figure 3) are somewhat less favorable than those on pure Fe, in 145 particular in term of sizes of crystallites (average size $40 \mathrm{~nm}$ at $117 \mathrm{GPa}$ ) and randomness of 146 the distribution (intensity variation are quite visible for both 100 and 101 reflections), but they 147 are still acceptable. The (002) reflection, still visible at all probed pressure, is very weak, as a 148 direct consequence of a small preferential orientation fully developed already at $59 \mathrm{GPa}$ and 149 not significantly evolving with pressure, with the c-axis preferentially aligned along the main 150 compression axis of the cell. Similar texture has been already reported in previous 151 experiments on iron [Wenk et al., 2000] and other metals with hcp structure [Merkel et al., 152 2006]. Such a moderately increased deviation from the ideal random distribution is reflected 153 into the fairly increased error bars on the velocities derived from the IXS data (deviation from 154 ideal average can affect velocities up to $2 \%$ ). 
At the highest compression the maximum observed difference in pressure across the sample chamber $(\sim 35 \mu \mathrm{m})$ is $<7 \mathrm{GPa}$ for $\mathrm{Fe}$ and $<10 \mathrm{GPa}$ for $\mathrm{Fe}-\mathrm{Si} 9$. Over the volume seen by IXS we obtain an average pressure of $167 \mathrm{GPa}(\mathrm{Fe})$, with a standard deviation of $2 \mathrm{GPa}$ and a standard error of $1 \mathrm{GPa}$, and an average pressure of $144 \mathrm{GPa}$ (Fe-Si9), with a standard deviation of $2 \mathrm{GPa}$ and a standard error of $1 \mathrm{GPa}$.

\section{Results}

The experimentally determined densities and velocities for hcp-Fe and hcp-Fe-Si9 are summarized in Table 1. The details are presented below.

The measured compressional and shear sound velocities as a function of density for hcp-Fe are plotted in Figure 4. These new measurements of $V_{P}$ are in very good agreement with the $\mathrm{V}_{\mathrm{P}}-\rho$ linear relationship recently proposed by fitting combined datasets derived from multiple techniques [Antonangeli and Ohtani, 2015], extending the data coverage at extreme pressures. We notice that the extrapolation of the established trend to higher density is in remarkable agreement with ab initio calculations at 0 K [Vočadlo et al., 2009; Sha and Cohen, 2010], clearly supporting a linear dependence of $V_{P}$ on density. The derived $V_{S}-\rho$ linear relationship is also in general agreement with results of ab initio calculations at $0 \mathrm{~K}$. We also noticed the good agreement between the slope of our $\mathrm{V}_{\mathrm{S}}-\rho$ trend with that obtained by the most recent nuclear resonant inelastic x-ray scattering (NRIXS) experiments [Murphy et al., 2013; Gleason et al., 2013; Liu et al., 2016], even if actual $\mathrm{V}_{\mathrm{S}}$ values derived by NRIXS are somewhat lower, between 3 to $8 \%$ depending upon datasets. Such a difference is at least partially due to the enrichment in heavier Fe isotopes of samples used for NRIXS studies with respect to sample of natural isotopic abundance used here. 
The measured compressional and shear sound velocities as a function of density for hcp-Fe-Si9 are shown in Figure 5. Our $\mathrm{V}_{\mathrm{P}}$ measurements on samples with 9 wt.\% Si are very close to previous IXS measurements on samples with 8 wt.\% Si [Mao et al., 2012], but they are systematically higher than early determination by NRIXS on samples with 8 wt.\% Si [ Lin et al., 2003]. Similar to the case of pure Fe, our measurements support a linear dependence of $\mathrm{V}_{\mathrm{P}}$ on $\rho$ for $\mathrm{Fe}-\mathrm{Si}$. The derived $\mathrm{V}_{\mathrm{S}}-\rho$ relationship can be well described by a second order polynomial (Figure 5).

Comparison of results obtained for $\mathrm{Fe}$ and $\mathrm{Fe}-\mathrm{Si} 9$ (Figure 6) show that $\mathrm{Si}$ alloying systematically increases $V_{P}$ at constant density over the investigated pressure range. Linear fits indicate that, even if $\mathrm{V}_{\mathrm{P}}$ of the Fe-Si9 alloy increases with density slower than pure $\mathrm{Fe}$, Fe-Si9 is still expected to have significantly higher $V_{P}$ than Fe at inner core density $(\sim 12390$ $\mathrm{m} / \mathrm{s}$ vs. $\sim 11680 \mathrm{~m} / \mathrm{s}$ at $13000 \mathrm{~kg} / \mathrm{m}^{3}$ ). On the other hand, the derived density evolution for $\mathrm{V}_{\mathrm{S}}$ of Fe-Si9 is such that the Si-bearing alloys is expected to have higher $\mathrm{V}_{\mathrm{S}}$ than pure Fe only up to $\rho \approx 11200 \mathrm{~kg} / \mathrm{m}^{3}$, with $\mathrm{V}_{\mathrm{S}}$ of Fe larger than $\mathrm{V}_{\mathrm{S}}$ of Fe-Si9 at inner core density $(\sim 5130 \mathrm{~m} / \mathrm{s} \mathrm{vs}$. $\sim 5890 \mathrm{~m} / \mathrm{s}$ at $13000 \mathrm{~kg} / \mathrm{m}^{3}$ ). This trend (i.e $\mathrm{V}_{\mathrm{P}}$ increasing with $\mathrm{Si}$ content and $\mathrm{V}_{\mathrm{S}}$ decreasing) has been reported as well by recent ab initio calculations of $\mathrm{Fe}-\mathrm{Si}$ alloys at core pressures [Martorell et al., 2016]. However, on the contrary to the case of pure Fe, the extrapolation of our experimental results for $\mathrm{Fe}-\mathrm{Si} 9$ does not agree with the calculations.

\section{Discussion}

Concerning hcp-Fe, we note a remarkable agreement between our new measurements, previous measurements by various techniques and $a b$ initio calculations for $V_{P}$, and a reasonable agreement for $\mathrm{V}_{\mathrm{S}}$. The established consensus provides very strong constraints on the linear dependence of velocities on density and on actual values of velocities of hcp-Fe at 
inner core densities and $300 \mathrm{~K}$ (Figure 4), which can by now be considered known within few

203 percent (with $\mathrm{V}_{\mathrm{P}}$ better constrained than $\mathrm{V}_{\mathrm{S}}$ ).

Somewhat less evident is the case for Si bearing hcp Fe-alloys. Literature data obtained

205 in the $\sim 40$ to $\sim 100 \mathrm{GPa}$ range on samples of the same nominal composition [Lin et al., 2003;

206 Mao et al., 2012] are in clear disagreement (Figure 5). Reasons for the discrepancy between

207 NRIXS [Lin et al., 2003] and IXS [Mao et al., 2012] data possibly include systematic

208 differences due to the techniques, or due to the sample's texture. The $V_{P}$ measured in this

209 study are in a good agreement with previous IXS determination at lower pressures [Mao et al.,

$2102012]$ and significantly extend the probed pressure range. In view of our new data, a sub-

211 linear relationship between $V_{P}$ and density, as proposed by Mao et al., [2012] on the basis of

212 data over a more restricted pressure range, seems not justified. Linear extrapolation of

213 experimental results to inner core density and comparison with calculations [Tsuchiya and

214 Fujibuki, 2009; Martorell et al., 2016] show however a disagreement, more important for $\mathrm{V}_{\mathrm{P}}$

215 than for $\mathrm{V}_{\mathrm{S}}$. The difference would be even more striking when considering a power-law sub-

216 linear extrapolation. In particular, the calculations seem to overestimate the effect of Si on $V_{P}$

217 of the Fe-Si alloys. We noticed that ab initio calculations on Fe-Si alloys, even when

218 performed at $0 \mathrm{~K}$, give quite conflicting results [Tsuchiya and Fujibuki, 2009; Martorell et al.,

219 2016], highlighting the difficulty in performing calculations taking into account the

220 configurational order/disorder inherent to alloys. Further investigation by both experiments

221 and theoretical calculations is necessary to resolve the discrepancy.

222 The direct comparison between results obtained on $\mathrm{Fe}$ and on Fe-Si9 allows us to

223 address the effect of Si content on the velocities of a hcp $\mathrm{Fe}_{1-\mathrm{x}} \mathrm{Si}_{\mathrm{x}}$ alloy in the limit of low to

224 moderate Si concentration (0 to $9 \mathrm{wt} . \%)$. The simplest approach is to use an ideal linear

225 mixing model [e.g. Badro et al., 2007; Antonangeli et al., 2010]. Using the reference relations

226 established here for pure Fe and the extrapolation of our measurements on $\mathrm{Fe}-\mathrm{Si}$, at the inner 
227 core density of $13000 \mathrm{~kg} / \mathrm{m}^{3}$ we get a variation $\sim+80 \mathrm{~m} / \mathrm{s}$ on $V_{P}$ and $\sim-80 \mathrm{~m} / \mathrm{s}$ on $V_{S}$ for each

228 wt.\% of Si (Figure 6). Measurements of $\mathrm{V}_{\mathrm{P}}$ on an Fe-Ni-Si alloy with $4.3 w t . \%$ Ni and 229 3.7wt.\% Si [Antonangeli et al., 2010] extrapolated to $13000 \mathrm{~kg} / \mathrm{m}^{3}$ yield $\mathrm{V}_{\mathrm{P}} \sim 12100 \mathrm{~m} / \mathrm{s}$, in 230 good agreement with our estimate of $\mathrm{V}_{\mathrm{P}} \sim 11980 \mathrm{~m} / \mathrm{s}$ for a $\mathrm{Fe}-\mathrm{Si}$ alloy with 3.7wt.\%Si 231 (difference $\sim-1 \%$ ). This agreement argues in favor of the suitability of the here-proposed 232 estimate. Moreover it suggests that the effect on the compressional sound velocity due to $\mathrm{Ni}$ 233 inclusion at level of 4 to $5 \mathrm{wt} . \%$ is minor. Further independent support also comes from the 234 good agreement observed between our predicted value of $\mathrm{V}_{\mathrm{P}} \sim 12160 \mathrm{~m} / \mathrm{s}$ and the extrapolation 235 of very new measurements on a Fe-Si alloy with 6wt.\% Si [Sakairi et al., Am. Min. in press.] 236 yielding $\mathrm{V}_{\mathrm{P}} \sim 11940 \mathrm{~m} / \mathrm{s}$ (difference $\sim+1.8 \%$ ).

In order to use our data to assess the Si abundance in the inner core by comparison with 238 seismological models, the effects of high temperature have to be accounted for. A velocity vs. 239 density representation, as the one proposed here, implicitly accounts for quasi-harmonic 240 effects, but anharmonic effects might be important as well, in particular on $\mathrm{V}_{\mathrm{S}}$ and for 241 temperatures approaching melting. Sound velocity measurements at simultaneous high 242 pressure and high temperature conditions are at the cutting edge of current technical 243 capabilities and only few datasets are available, mostly for pure Fe [e.g. Antonangeli et al., 244 2012; Mao et al., 2012; Ohtani et al., 2013; Sakamaki et al., 2015]. If we model high245 temperature effects for Fe following Sakamaki et al. [2015], $\mathrm{V}_{\mathrm{P}}$ is expected to be lowered by $246 \sim-0.09 \mathrm{~m} / \mathrm{s} \mathrm{K}^{-1}$ at the constant density of $13000 \mathrm{~kg} / \mathrm{m}^{3}$. The orange arrow in Figure 4 247 highlights the magnitude of the expected reduction of $\mathrm{V}_{\mathrm{P}}$ for $\mathrm{T}$ up to $\sim 7000 \mathrm{~K}$. Alternatively 248 we can model temperature-induced softening (in this case for both $V_{P}$ and $V_{S}$ ) following 249 calculations by Martorell et al., [2013]. As these calculations have been performed at 250 constant pressure, while here we are interested in the effects at constant density, we corrected 251 the computed values according to the measured density dependence of sound velocities to 
compensate for the effects due to density variation with increasing temperature. Once limiting

253 to $\mathrm{T}$ up to $7000 \mathrm{~K}$, the estimated lowering of $\mathrm{V}_{\mathrm{P}}$ and $\mathrm{V}_{\mathrm{S}}$ are, respectively, $\sim-0.12 \mathrm{~m} / \mathrm{s} \mathrm{K}^{-1}$ and $254 \sim-0.32 \mathrm{~m} / \mathrm{s} \mathrm{K}^{-1}$ at the constant density of $13000 \mathrm{~kg} / \mathrm{m}^{3}$. The violet arrows in Figure 4 highlights the magnitude of the expected reduction of $V_{P}$ and $V_{S}$ for $T$ up to $\sim 7000 \mathrm{~K}$. In qualitative agreement with recent calculations, for $\mathrm{Fe}$, temperature effects alone permit to match inner core velocities (but not densities, which remain too high for pressures in the range 330 to $360 \mathrm{GPa}$ ). In the case of Fe-Si alloys we can only rely on calculations [Martorell et al., 2016], which, once corrected as in the case of Fe, yield for a sample with $3.2 \mathrm{wt} \% \mathrm{Si}$ a reduction of $\mathrm{V}_{\mathrm{P}}$ and $\mathrm{V}_{\mathrm{S}}$ of, respectively, $\sim-0.12 \mathrm{~m} / \mathrm{s} \mathrm{K}^{-1}$ and $\sim-0.34 \mathrm{~m} / \mathrm{s} \mathrm{K}^{-1}$, and for a sample with $6.7 \mathrm{wt} \% \mathrm{Si}$ a reduction of $\sim-0.20 \mathrm{~m} / \mathrm{s} \mathrm{K}^{-1}$ and $\sim-0.23 \mathrm{~m} / \mathrm{s} \mathrm{K}^{-1}$, at the constant density of $13000 \mathrm{~kg} / \mathrm{m}^{3}$. We note that theoretical estimates for pure Fe and a Fe-Si alloy with $3.2 \mathrm{wt} . \% \mathrm{Si}$ are very close, while those for a Fe-Si with $6.7 \mathrm{wt} . \% \mathrm{Si}$ differ, with an effect on $\mathrm{V}_{\mathrm{P}}$ almost double and an effect on $\mathrm{V}_{\mathrm{S}}$ about $30 \%$ smaller. The arrows in Figure 5 highlights the magnitude of the expected reduction of $\mathrm{V}_{\mathrm{P}}$ and $\mathrm{V}_{\mathrm{S}}$ for $\mathrm{T}$ up to $\sim 7000 \mathrm{~K}$ if we apply to our measurements on Fe-Si9 the correction estimated for samples with 3.2wt.\% Si (dark blue arrows) or that for samples with $6.7 \mathrm{wt} . \% \mathrm{Si}$ (green arrows). Similarly to the case of Fe, if temperature effects are as large as expected according to calculations, temperature alone might be enough to explain inner core velocities (but again, not the densities, too low for pressures in the 330 to $360 \mathrm{GPa}$ range for samples with 9 wt.\% Si [Tateno et al., 2015]).

If we assume temperature effects at the constant density of $13000 \mathrm{~kg} / \mathrm{m}^{3}$ of $\sim-0.20 \mathrm{~m} / \mathrm{s}$ $\mathrm{K}^{-1}$ for $\mathrm{V}_{\mathrm{P}}$ and $\sim-0.23 \mathrm{~m} / \mathrm{s} \mathrm{K}^{-1}$ for $\mathrm{V}_{\mathrm{S}}$ (as from estimates from calculations on a sample with $6.7 \mathrm{wt} \% \mathrm{Si}$ ) we match PREM values of $\mathrm{V}_{\mathrm{P}}$ and $\mathrm{V}_{\mathrm{S}}$ for a $\mathrm{Si}$ concentration of $10 \pm 1 \mathrm{wt} . \%$ and $\mathrm{T}$ between 6500 and $6700 \mathrm{~K}$. This solution however is not acceptable, as such Fe-Si alloy is expected to have the right density only for pressures well above $360 \mathrm{GPa}$ [Tateno et al., 2015]. If we assume temperature effects at the constant density of $13000 \mathrm{~kg} / \mathrm{m}^{3}$ of $\sim-0.12 \mathrm{~m} / \mathrm{s} \mathrm{K}^{-1}$ for 
$277 \mathrm{~V}_{\mathrm{P}}$ and $\sim-0.33 \mathrm{~m} / \mathrm{s} \mathrm{K}^{-1}$ for $\mathrm{V}_{\mathrm{S}}$ (as from estimates from calculations on pure $\mathrm{Fe}$ and on a

278 sample with $3.2 \mathrm{wt} \% \mathrm{Si}$ ) we obtain PREM values of $\mathrm{V}_{\mathrm{P}}$ and $\mathrm{V}_{\mathrm{S}}$ for a $\mathrm{Si}$ concentration of $3 \pm 2$ 279 wt.\% and T between 6200 and 6500 K. P-V-T relation for a Fe-Si alloy with 3 wt.\% Si has

280 not been experimentally determined yet, but calculations suggest such an alloy to have a 281 density of $\sim 13160 \mathrm{~kg} / \mathrm{m}^{3}$ at $360 \mathrm{GPa}$ and $6400 \mathrm{~K}$ [Martorell et al., 2016], thus making this 282 solution acceptable. Furthermore, an inner core temperature of $6200-6500 \mathrm{~K}$ is compatible 283 with estimates based on measurements of the Fe and Fe-Si alloys melting curve [Anzellini et 284 al., 2013; Morard et al., 2011]. However, as already mentioned, the most recent experimental 285 determination of temperature dependence of $\mathrm{V}_{\mathrm{P}}$ for Fe by Sakamaki et al. [2016] argues for a 286 less important temperature-induced lowering with respect to that proposed by calculations. If 287 we assume temperature effects at the constant density of $13000 \mathrm{~kg} / \mathrm{m}^{3}$ of $\sim-0.09 \mathrm{~m} / \mathrm{s} \mathrm{K}^{-1}$ for $288 \mathrm{~V}_{\mathrm{P}}$ as from Sakamaki et al. [2016], we match PREM value of $\mathrm{V}_{\mathrm{P}}$ for $\sim 1 \mathrm{wt. \%}$ Si at $6300 \mathrm{~K}$ 289 and $\sim 2$ wt.\% Si at $7300 \mathrm{~K}$. The last solution is not acceptable as a Fe-Si alloy is not solid at 290 such a high temperatures [Morard et al., 2011; Anzellini et al., 2013]. Furthermore, 291 irrespectively whether we assume a temperature effect on $\mathrm{V}_{\mathrm{S}}$ of $\sim-0.33 \mathrm{~m} / \mathrm{s} \mathrm{K}^{-1}$ (as from 292 estimates from calculations on pure $\mathrm{Fe}$ and a Fe-Si alloy with $3.2 \mathrm{wt} . \% \mathrm{Si}$ ), or $\sim-0.23 \mathrm{~m} / \mathrm{s} \mathrm{K}^{-1}$ 293 (as from estimates from calculations on Fe-Si alloy with $6,7 \mathrm{wt} . \% \mathrm{Si}$ ), or $\sim-0.24 \mathrm{~m} / \mathrm{s} \mathrm{K}^{-1}$ for $294 V_{S}$ (scaling the estimates from calculations on pure Fe in line with the reduced effect on $V_{P}$ ), 295 there is no solution matching PREM values of $V_{P}$ and $V_{S}$ for a fixed Si content. Further 296 constraints on the effects of high-temperature on sound velocities thus remain crucial to 297 reliably estimate the Si content in the inner core.

\section{Conclusions}

We carried out sound velocity and density measurements on solid hcp-Fe and an hcp301 Fe-Si alloy with 9 wt.\% Si up to $\sim 170$ and $\sim 140 \mathrm{GPa}$, respectively. The experimentally 
established $V_{P}-\rho$ and $V_{S}-\rho$ relations for pure $F e$ are in good agreement with results from ab initio calculations and clearly show that both compressional and shear velocities scale linearly with density at $300 \mathrm{~K}$ (Figure 4). At $300 \mathrm{~K}$ and the inner core density of $13000 \mathrm{~kg} / \mathrm{m}^{3}$, the reference values for $V_{P}$ and $V_{S}$ are respectively $11680 \pm 250 \mathrm{~m} / \mathrm{s}$ and $5890 \pm 360 \mathrm{~m} / \mathrm{s}$. Measurements on the Fe-Si alloy with 9 wt.\% Si allowed us to discriminate between previous inconsistent datasets (Figure 5) and to propose $V_{P}-\rho$ and $V_{S}-\rho$ relations for Fe-Si9. These results are used to address the presence and abundance of Si in the Earth's inner core. al., 2015] or even by combined density and compressional sound velocity [e.g. Badro et al., 2007; Mao et al., 2012; Ohtani et al., 2013] can be used to exclude possibilities, but it is necessary to simultaneously consider $\mathrm{V}_{\mathrm{P}}, \mathrm{V}_{\mathrm{S}}$ and $\rho$ to propose a consistent composition for the

313 Earth's inner core. Qualitatively, at inner core conditions, high temperature reduces sound 314 velocities, even at constant density, while Si alloying at level of 9 wt.\%, lowers $\rho$, increases $V_{P}$ and decreases $V_{S}$ with respect to pure Fe. These same effects have been very recently suggested by calculations on Fe-Si alloys [Martorell et al., 2016], as well as for carbon alloys 317 [Caracas, 2017]. Assuming an ideal linear mixing model to be valid for low to moderate Si 318 concentration $(<10 \mathrm{wt} . \%)$, we quantitatively evaluate the effect in $\sim+80 \mathrm{~m} / \mathrm{s}$ on $\mathrm{V}_{\mathrm{P}}$ and $\sim-80$ $\mathrm{m} / \mathrm{s}$ on $\mathrm{V}_{\mathrm{S}}$ for each wt.\% of $\mathrm{Si}$ at the inner core density of $13000 \mathrm{~kg} / \mathrm{m}^{3}$. Further studies on samples of intermediate compositions will allow refinement of this estimation.

We explored the possible solutions for an hcp-Fe-Si alloy whose density, compressional and shear sound velocities would match PREM values for pressures in the range 330 to 360

$323 \mathrm{GPa}$ and temperatures in the range 4000 to $7500 \mathrm{~K}$. The existence of a solution and the 324 amount of Si necessary to match the seismological observations strongly depends on the way 325 we model anharmonic effects on sound velocities at high temperature and on core temperature. 326 In particular, we obtain possible solutions only for large temperature corrections, relatively 
high core temperatures (with T comprised between 6200 and $6500 \mathrm{~K}$ ), and for Si content not exceeding $3 \pm 2 \mathrm{wt} . \% \mathrm{Si}$. Accordingly, the current results do not support the presence of Si in the inner core at a level of 6 to $8 \mathrm{wt} . \%$ as recently proposed [Mao et al., 2012; Fischer et al., 2015; Tateno et al., 2015]. On the sole basis of density and sound velocities systematics, we cannot discriminate between results proposing little (up to 4 wt.\%) [e.g. Badro et al., 2007; Antonangeli et al., 2010] to no presence [Martorell et al., 2016] of Si in the inner core. More experimental and theoretical work on Fe-Si alloys remains to be performed, so as to extend the directly probed pressure and temperature range and to check the limit of the ideal mixing approximation. We also encourage performing calculations not only at actual core conditions, but as well at conditions where experimental data exist, so as to validate theoretical treatments of alloys.

\section{Acknowledgments}

This work was supported by the Investissements d'Avenir programme (reference ANR11-IDEX-0004-02) and more specifically within the framework of the Cluster of Excellence MATériaux Interfaces Surfaces Environnement (MATISSE) led by Sorbonne Universités (grant to DA). The research was also supported by the Carnegie Institution for Science and NSF (grant EAR-1619868 to YF). Authors wish to thank Sébastien Merkel for discussion about texture and preferential orientations.

\section{References}

Antonangeli, D., F. Occelli, H. Requardt, J. Badro, G. Fiquet, M. Krisch (2004), Elastic anisotropy in textured hep-iron to $112 \mathrm{GPa}$ from sound wave propagation measurements, Earth Planet. Sci. Lett. 225, 243-251. 
Antonangeli, D., J. Siebert, J. Badro, D.L. Farber, G. Fiquet, G. Morard, F.J. Ryerson (2010), Composition of the Earth's inner core from high-pressure sound velocity measurements in Fe-Ni-Si alloys, Earth Planet. Sci. Lett. 295, 292-296.

Antonangeli, D., T. Komabayashi, F. Occelli, E. Borissenko, A.C. Walters, G. Fiquet, Y. Fei, (2012), Simultaneous sound velocity and density measurements of hcp iron up to 93 GPa and $1100 \mathrm{~K}$ : An experimental test of the Birch's law at high temperature, Earth Planet. Sci. Lett. 331-332, 210-214.

Antonangeli, D., and E. Ohtani (2015), Sound velocity of hcp-Fe at high pressure: experimental constraints, extrapolations and comparison with seismic models, Prog. Earth Planet. Sci. 2, 3.

Antonangeli, D., G. Morard, N.C. Schmerr, T. Komabayashi, M. Krisch, G. Fiquet, Y. Fei (2015), Toward a mineral physics reference model for the Moon's core, Proc. Natl. Acad. Sci. USA 112, 3916-3919.

Anzellini, S., A. Dewaele, M. Mezouar, P. Loubeyre, G. Morard (2013), Melting of iron at Earth's inner core boundary based on fast x-ray diffraction, Science 340, 464-466.

Badro, J., G. Fiquet, F. Guyot, E. Gregoryanz, F. Occelli, D. Antonangeli, M. d'Astuto (2007), Effect of light elements on the sound velocities in solid iron: implications for the composition of Earth's core, Earth Planet. Sci. Lett. 254, 233-238.

Birch, F. (1952). Elasticity and constitution of the Earth's interior, J. Geophys. Res. 57, 227286.

Bosak, A., M. Krisch, I. Fischer, S. Huotari, G. Monaco (2007), Inelastic x-ray scattering from polycrystalline materials at low momentum transfer, Phys. Rev. B 75, 064106. 
373 Bosak, A., M. Krisch, A. Chumakov, I.A. Abrisokov, L. Dubrovinsky (2016), Possible artifacts in inferring seismic properties from X-ray data, Phys. Earth Planet. Inter.260, $14-19$.

Caracas., R. (2017). The influence of carbon on the seismic properties of solid iron, Geophys. Res. Lett. 44, 128-134.

Crowhurst, J.C., A.F. Goncharov, J.M. Zaug (2004), Impulsive stimulated light scattering from opaque materials at high pressure, J. Phys. Condens. Matter. 16, S1137-S1142.

Decremps, F., D. Antonangeli, M. Gauthier, S. Ayrinhac, M. Morand, G. Le Marchand, F. Bergame, J. Philippe (2014), Sound velocity measurements of iron up to $152 \mathrm{GPa}$ by picosecond acoustics in diamond anvil cell, Geophys. Res. Lett. 41, 1459.

Dziewonski, A.M., and D.L. Anderson (1981). Preliminary reference Earth model, Phys. Earth Planet. Inter. 25, 297-356.

Fiquet, G., J. Badro, F. Guyot, H. Requardt, M. Krisch (2001). Sound velocities in iron to 110 gigapascals, Science 291, 468-471.

Fiquet, G., J. Badro, E. Gregoryanz, Y. Fei, F. Occelli (2009). Sound velocity in iron carbide $\left(\mathrm{Fe}_{3} \mathrm{C}\right)$ at high pressure: Implications for the carbon content of the Earth's inner core, Phys. Earth Planet. Inter. 172, 125-129.

Fischer, R.A., Y. Nakajima, A.J. Campbell, D.J. Frost, D. Harries, F. Langenhorst, N. Miyajima, K. Pollok, D.C. Rubie (2015), High pressure metal-silicate partitioning of Ni, Co, V, Cr, Si, and O, Geochim. Cosmochim. Acta 167, 177-194.

Fei, Y. (2017). Unpublished data. 
Fei, Y., C. Murphy, Y. Shibazaki, A. Shahar, and H. Huang (2016), Thermal equation of state of hcp-iron: Constraint on the density deficit of Earth's solid inner core, Geophys. Res. Lett. 43, 6837-6843.

Gleason, A.E., W.L. Mao, J.Y. Zhao (2013), Sound velocities for hexagonally closepacked iron compressed hydrostatically to $136 \mathrm{GPa}$ from phonon density of states, Geophys. Res. Lett. 40, 2983-2987.

Guinan, M.W., and D.N. Beshers (1968), Pressure derivatives of the elastic constants of $\alpha$ iron to $110 \mathrm{kbs}$, J. Phys. Chem. Solids 29, 541-549.

Lin, J.-F., V.V. Struzhkin, W. Sturhahn, E. Huang, J. Zhao, Y.H. Hu, E.E. Alp, H.-K. Mao, N. Boctor, J. Hemley (2003), Sound velocities of iron-nickel and iron-silicon alloys at high pressures. Geophys. Res. Lett. 30, 2112.

Liu, J., J.-F. Lin, A. Alatas, A., M.Y. Hu, J. Zhao, L. Dubrovinsky (2016), Seismic parameters of hcp-Fe alloyed with Ni and Si in the Earth's inner core, J. Geophys. Res. Solid Earth $121,610-623$.

Mao, H.K, Y. Wu, L.C. Chen, J.F. Shu, A.P. Jephcoat (1990), Static compression of iron to $300 \mathrm{GPa}$ and $\mathrm{Fe}_{0.8} \mathrm{Ni}_{0.2}$ alloy to $260 \mathrm{GPa}$ : Implications for composition of the core, $J$. Geophys. Res. 95, 21737-21742.

Mao, H.K., J. Shu, G. Shen, R.J. Hemley, B. Li, A.K. Singh (1998), Elasticity and rheology of iron above $220 \mathrm{GPa}$ and the nature of the Earth's inner core. Nature 396, 741-743; correction (1999) Nature 399, 80.

Mao, Z., J.-F. Lin, J. Liu, A. Alatas, L. Gao, J. Zhao, H.-K. Mao (2012), Sound velocities of Fe and Fe-Si alloy in the Earth's core, Proc. Natl. Acad. Sci. USA 109, 10239-10244.

Martorell, B., L. Vočadlo, J. Brodholt, I.G. Wood (2013), Strong pre-melting effect in the elastic properties of hcp-Fe under inner-core conditions, Science 342, 466-468. 
Martorell, B., I.G. Wood, J., Brodholt, L. Vočadlo (2016), The elastic properties of hcp$\mathrm{Fe}_{1-\mathrm{x}} \mathrm{Si}_{\mathrm{x}}$ at Earth's inner-core conditions, Earth Planet. Sci. Lett. 451, 89-96.

Merkel, S., N. Miyajima, D. Antonangeli, G. Fiquet, T. Yagi (2006). Lattice preferred orientation and stress in polycrystalline hcp-Co plastically deformed under high pressure, J. Appl. Phys. 100, 023510.

Morard, G., D. Andrault. N. Guignot, J. Siebert, G. Garbarino, D. Antonangeli (2011), Melting of Fe-Ni-Si and Fe-Ni-S alloys at megabar pressures: implications for the coremantle boundary temperature, Phys. Chem. Minerals 38, 767-776.

Murphy, C.A., J.M. Jackson, W. Sturhahn (2013), Experimental constraints on the thermodynamics and sound velocities of hep-Fe to core pressures, J. Geophys. Res. Solid Earth 118, 1-18.

Ohtani, E., Y. Shibazaki, T. Sakai, K. Mibe, H. Fukui, S. Kamada, T. Sakamaki, Y. Seto, S. Tsutsui, A.Q.R. Baron (2013), Sound velocity of hexagonal close-packed iron up to core pressures, Geophys. Res. Lett. 40, 5089-5094.

Prescher, C., and V.B. Prakapenka (2015), DIOPTAS: a program for reduction of twodimensional X-ray diffraction data and data exploration, High Pressure Research 35, $223-230$.

Sakai, T., S. Takahashi, N. Nishitani, I. Mashini, E. Ohtani, N. Hirao (2014), Equation of state of pure iron and Fe0.9Ni0.1 alloy up to 3 Mbar, Phys. Earth Planet. Inter. 228, 114-126.

Sakairi, T., T. Sakamaki, E. Ohtani, H. Fukui, S. Kamada, S. Tsutsui, H. Uchiyama, A.Q.R. Baron (2017), American Mineralogist, in press. DOI: http://dx.doi.org/10.2138/am2018-6072.

Sakamaki, T., E. Ohtani, H. Fukui, S. Kamada, S. Takahashi, T. Sakairi, A. Takahata, T. Sakai, S. Tsutsui, D. Ishikawa, R. Shiraishi, Y. Seto, T. Tsuchiya, A.Q.R. Baron (2016), 
Constraints on Earth's inner core composition inferred from measurements of the sound velocity of hcp-iron in extreme conditions, Sci. $A d v .2$, e1500802.

444 Sha, X., and R.E. Cohen (2010), Elastic isotropy of $\varepsilon$-Fe under Earth's core conditions, Geophys. Res. Lett. 37, L10302.

446

Siebert, J., J. Badro, D. Antonangeli, F.J. Ryerson (2013), Terrestrial accretion under oxidizing conditions, Science 339, 1194-1197.

Tateno, S., K. Hirose, Y. Ohishi, Y. Tatsumi (2010), The structure of iron in the Earth's core, Science 330, 359-361.

Tateno, S., Y. Kuwayama, K. Hirose, Y. Ohishi (2015), The structure of Fe-Si alloy in the Earth's inner core, Earth Planet. Sci. Lett. 418, 11-19.

Tsuchiya, T., and M. Fujibuki (2009), Effects of Si on the elastic property of Fe at Earth's inner core pressures: Frist principles study, Phys. Earth Planet. Inter. 174, 212-219.

Vočadlo, L., D. Dobson, I.G. Wood (2009), Ab initio calculations of the elasticity of hcp-Fe as a function of temperature at inner-core pressure, Earth Planet. Sci. Lett. 288, 534 538.

Wenk, H.R., S. Matthies, R.J. Hemley, H.-K. Mao, J. Shu (2000), The plastic deformation of iron at pressures of the Earth's inner core, Nature 405, 1044-1047.

Wenk, H.R., I. Lonardelli, S. Merkel, L. Miyagi, J. Pehl, S. Speziale, C.E. Tommaseo (2006), Deformation textures produced in diamond anvil experiments, analyzed in radial diffraction geometry, J. Phys.: Cond. Matter 18, S933-S947.

Zhang, J. and F. Guyot (1999), Thermal equation of state of iron and $\mathrm{Fe}_{0.91} \mathrm{Si}_{0.09}$, Phys. Chem. Miner. 26, 206-211. 

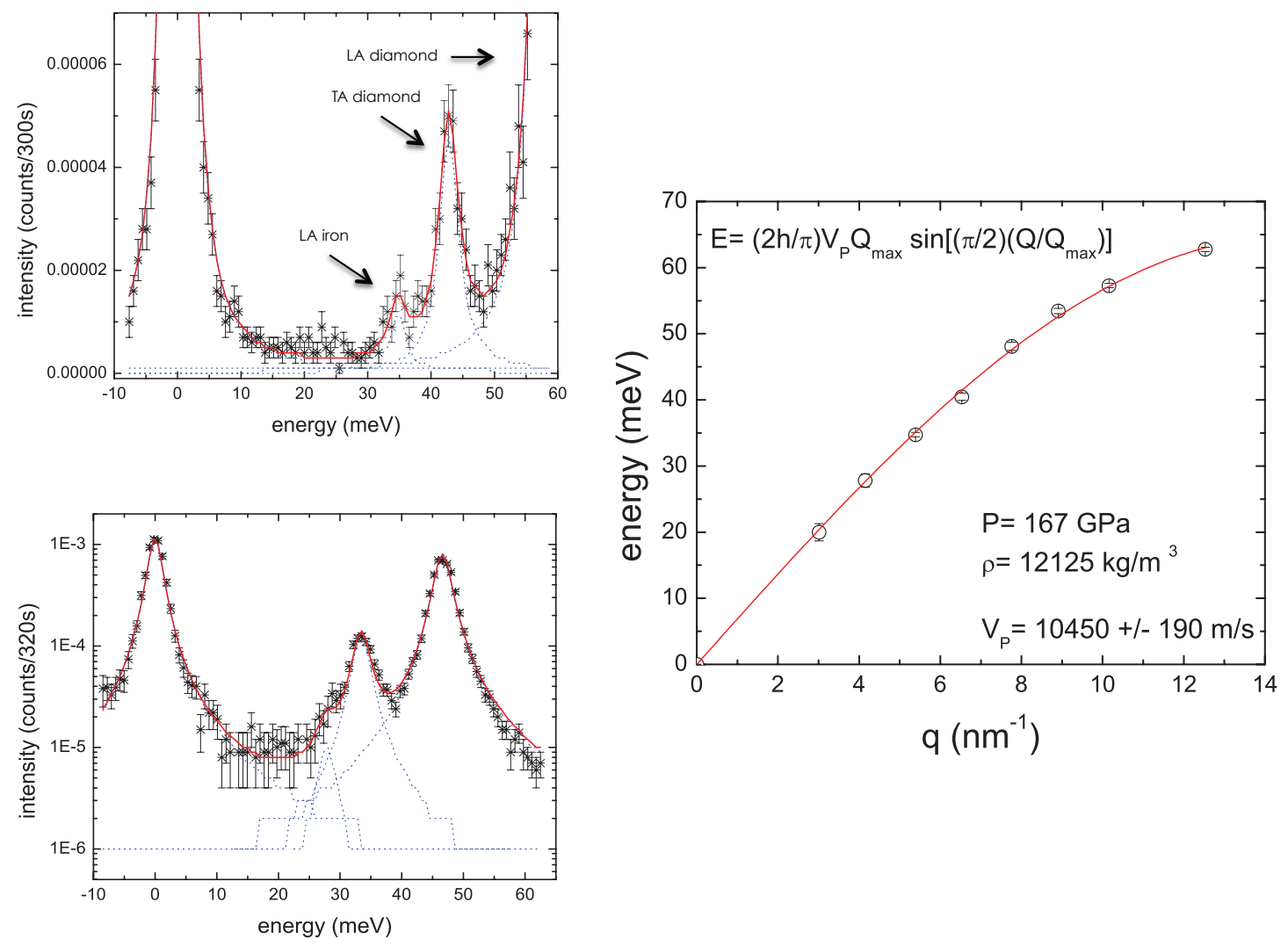

Figure 1. Examples of IXS spectra (left) and aggregate phonon dispersion (right)

obtained for pure-Fe at the highest investigated pressure $\left(\rho=12125 \mathrm{~kg} / \mathrm{m}^{3}\right.$, corresponding to $\sim 167 \mathrm{GPa}$ ). Up left: IXS spectrum for $\mathrm{q}=5.39 \mathrm{~nm}^{-1}$; bottom left IXS spectrum for $\mathrm{q}=4.15$ $\mathrm{nm}^{-1}$. IXS spectra are characterized by an elastic line, centered around zero, and inelastic

471 features, assigned for increasing energy to the longitudinal acoustic (LA) aggregate phonon of 472 iron and the transverse acoustic (TA) and longitudinal acoustic (LA) phonons of diamond. 473 The experimental points and error bars are shown together with the best-fit (red line) and 474 individual excitations (dashed blue lines). Sample phonons for q of $5.39 \mathrm{~nm}^{-1}$ and higher are 475 well resolved and visible in linear scale, while for smaller q values, sample phonons and TA 476 phonon of diamonds get very close, and sample phonons become a shoulder on the low477 energy side of the TA phonon of diamond, better visible in logarithmic scale. 


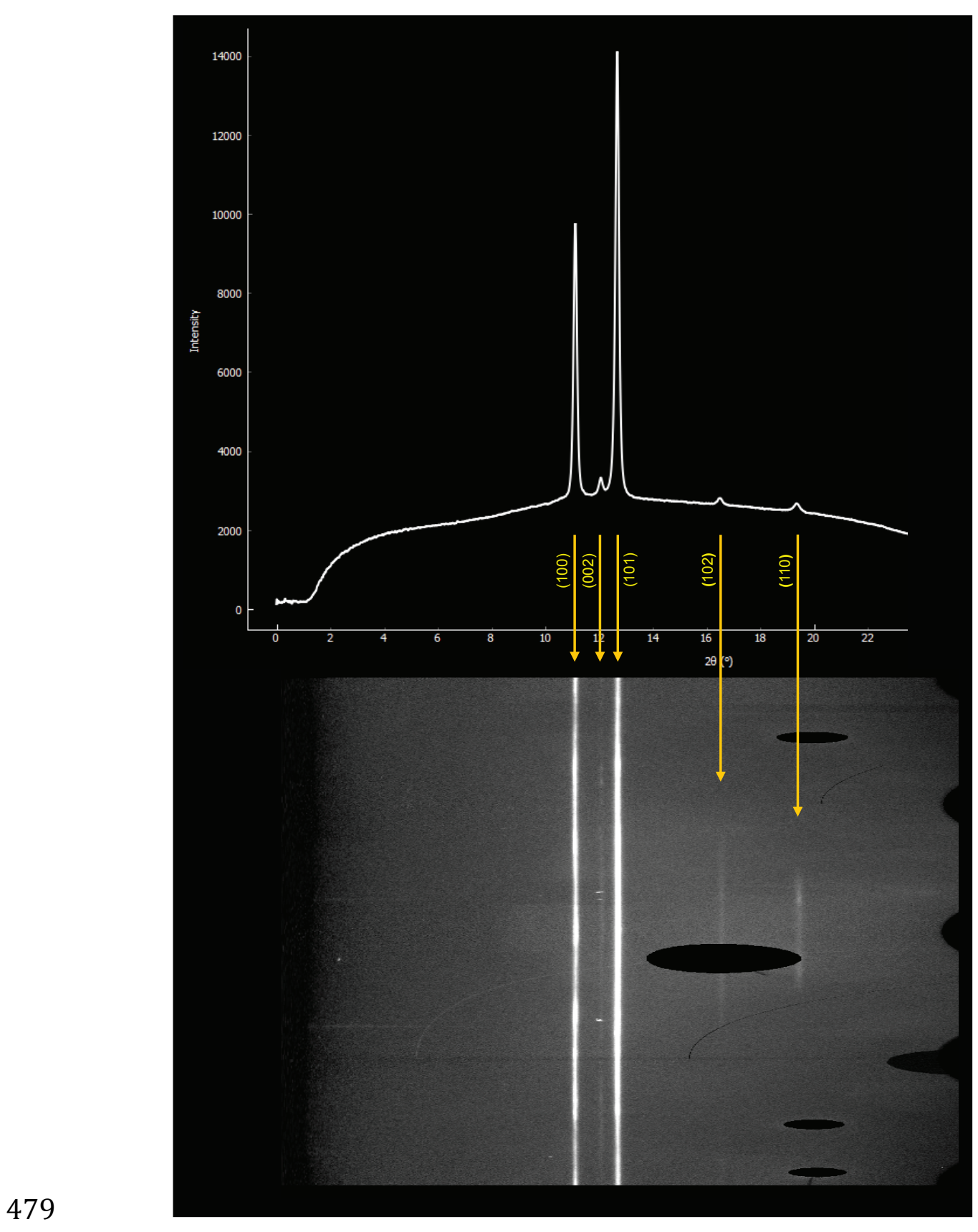

Figure 2. Example of integrated diffraction pattern collected on pure hcp-Fe at 482 P 167 GPa (top) and caked into a rectilinear projection (bottom). 2D diffraction images 483 have been integrated using Dioptas [Prescher and Prakapenka, 2015]. 


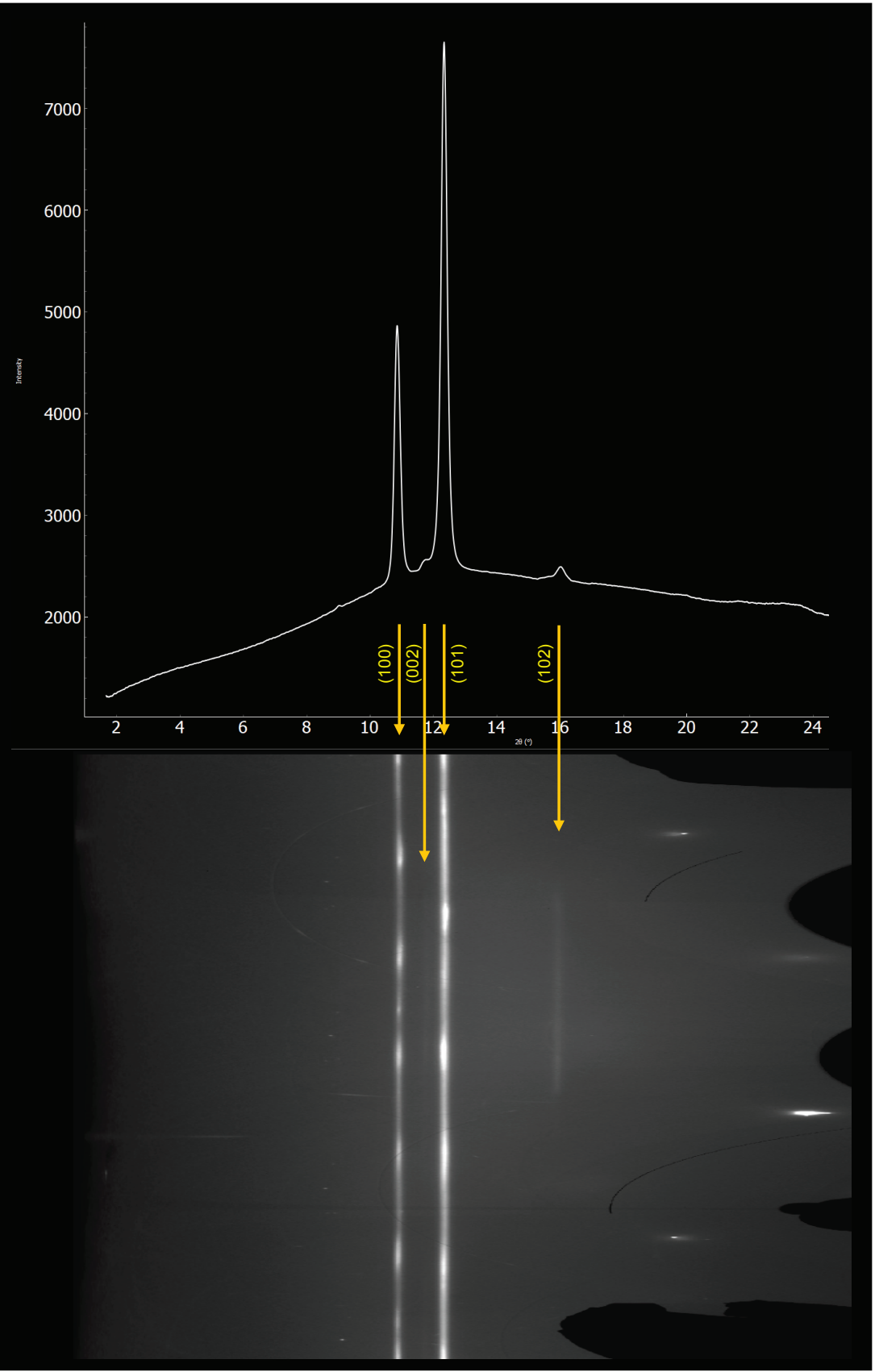

489 have been integrated using Dioptas [Prescher and Prakapenka, 2015]. 


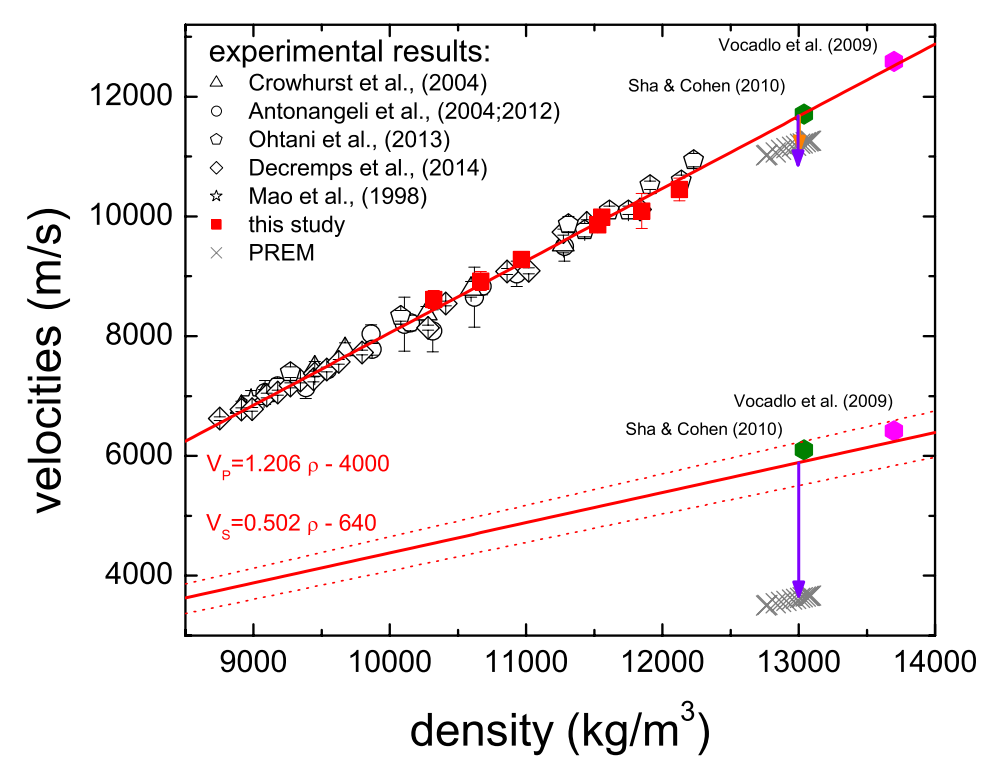

494 at $\mathbf{3 0 0} \mathbf{K}$ as a function of density. Results of this study are compared with a selection of 495 published measurements at $300 \mathrm{~K}$ [Mao et al., 1998; Crowhurst et al., 2004; Antonangeli et al., 496 2004, 2012; Ohtani et al., 2013; Decremps et al., 2014] (for further details see Antonangeli 497 and Ohtani [2015]), ab initio calculations at $0 \mathrm{~K}$ and $295 \mathrm{GPa}$ [Vočadlo et al., 2009] and at 0 $498 \mathrm{~K}$ and $13040 \mathrm{~kg} / \mathrm{m}^{3}$ [Sha and Cohen, 2010]. PREM [Dziewonski and Anderson, 1981] is 499 reported as crosses. Solid lines show the established linear $V_{\mathrm{P}-} \rho$ and $\mathrm{V}_{\mathrm{S}}-\rho$ relationships. 500 Dotted lines show confidence level on the derived $\mathrm{V}_{\mathrm{S}}$. Arrows indicate possible magnitude of 501 anharmonic effects up to $7000 \mathrm{~K}$ (see text). 


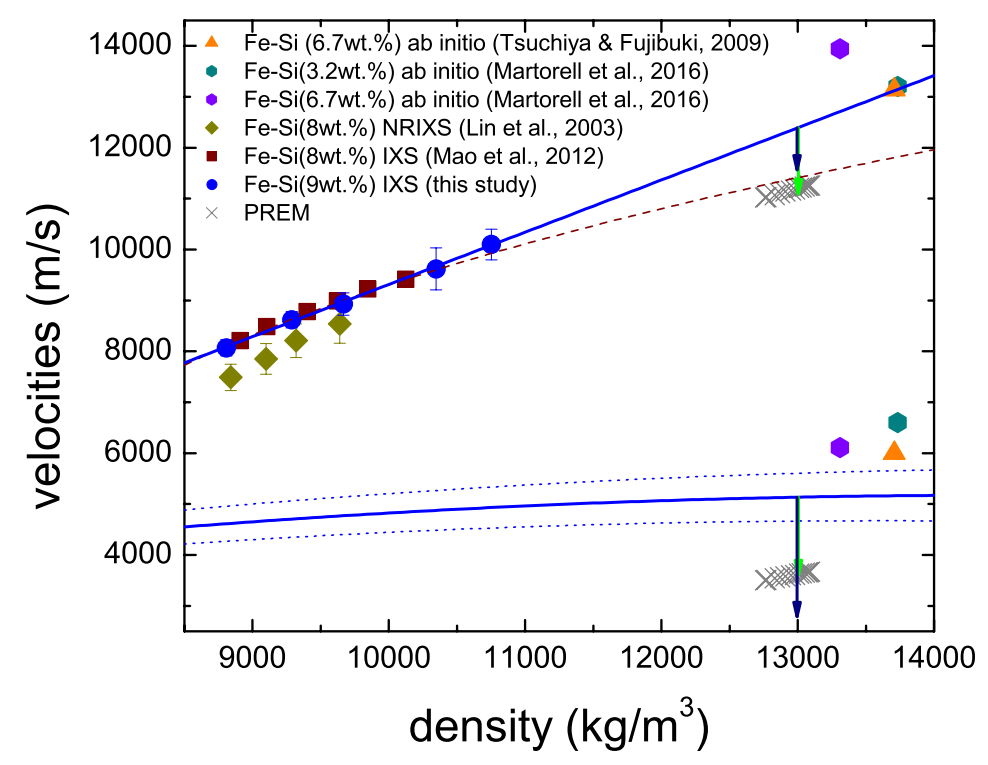

503

Figure 5. Aggregate compressional $\left(V_{P}\right)$ and shear $\left(V_{S}\right)$ sound velocities of hcp-Fe-

$506 \mathrm{Si} 9$ at $300 \mathrm{~K}$ as a function of density. Results of this study are compared with measurements

507 at $300 \mathrm{~K}$ on a hep-Fe-Si alloy with 8 wt.\% Si by NRIXS [Lin et al., 2003] and by IXS [Mao et

508 al., 2012] as well as with results of ab initio calculations at $0 \mathrm{~K}$ and $360 \mathrm{GPa}$ on an hcp-Fe-Si

509 alloy with 6.7 wt.\% Si [Tsuchiya and Fujibuki, 2009] and at $0 \mathrm{~K}$ and $360 \mathrm{GPa}$ on hcp-Fe-Si

510 alloys with 3.2 and 6.7 wt.\% Si [Martorell et al., 2016]. PREM [Dziewonski and Anderson,

511 1981] is reported as crosses. Solid lines show the proposed $V_{P}-\rho\left(V_{P}=1.026 \times \rho-946\right)$ and $V_{S}-\rho$

$512\left(\mathrm{~V}_{\mathrm{S}}=1530+0.503 \times \rho-1.736 \times 10^{-5} \times \rho^{2}\right)$ relationships. Dotted lines show confidence level on the

513 derived $\mathrm{V}_{\mathrm{S}}$. The dashed line is the empirical power-law function used by Mao et al., [2012] to

514 describe their $\mathrm{V}_{\mathrm{P}-} \rho$ data. Arrows indicate possible magnitude of anharmonic effects up to

$5157000 \mathrm{~K}$ (see text). 


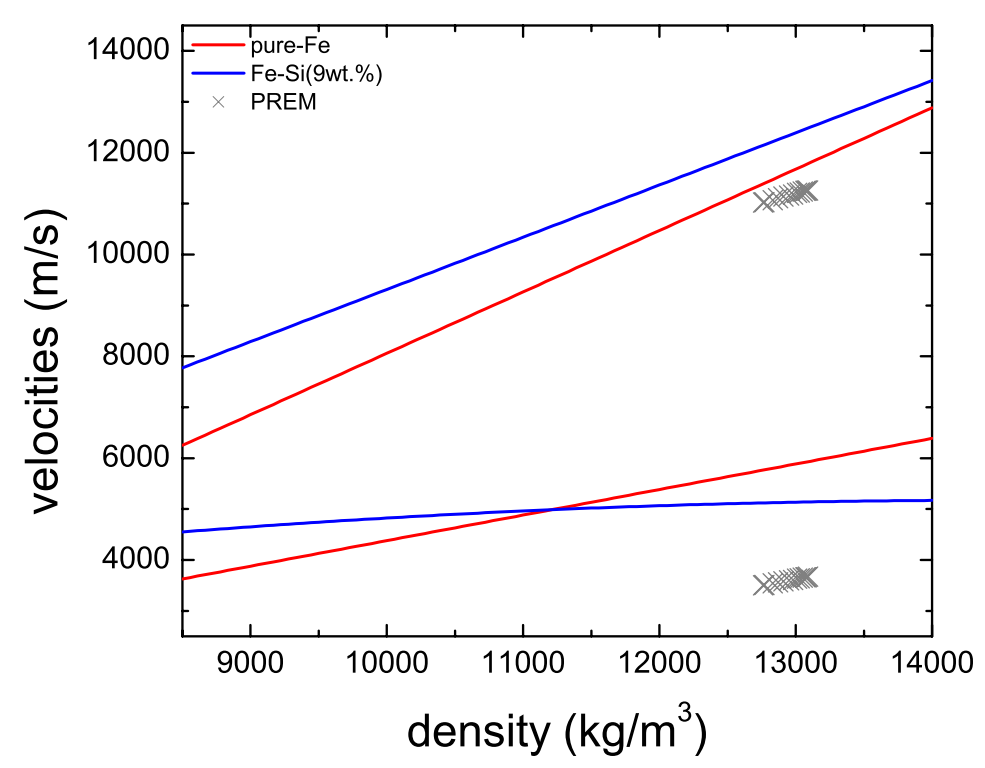

517

518

519 Figure 6. Comparison of the proposed density dependence of the aggregate

520 compressional $\left(V_{P}\right)$ and shear $\left(V_{S}\right)$ sound velocities of hcp-Fe (red) and hcp-FeSi9 (blue)

521 extrapolated to core density, along with PREM [Dziewonski and Anderson, 1981] shown

522 as crosses. 
524 estimated from measured diffraction patterns are reported as well. See text for discussion of 525 pressure uncertainties and pressure gradients. Assuming different equation of state for hcp-Fe 526 leads to a maximum difference in the reported pressure of less than $10 \mathrm{GPa}$ at the highest 527 density when using equation of state from Mao et al., [1990].

\begin{tabular}{|c|c|c|c|}
\hline Sample & Density $\left(\mathrm{kg} / \mathrm{m}^{3}\right)$ & Pressure (GPa) & $V_{P}(\mathbf{m} / \mathbf{s})$ \\
\hline hcp-Fe & 10325 & 63 & $8610 \pm 150$ \\
\hline hcp-Fe & 10665 & 79 & $8920 \pm 160$ \\
\hline hcp-Fe & 10965 & 96 & $9280 \pm 90$ \\
\hline hcp-Fe & 11525 & 124 & $9860 \pm 110$ \\
\hline hcp-Fe & 11555 & 126 & $9990 \pm 120$ \\
\hline hcp-Fe & 11850 & 146 & $10090 \pm 290$ \\
\hline hcp-Fe & 12125 & 167 & $10450 \pm 190$ \\
\hline hcp-Fe-Si9 ${ }^{\mathrm{a}}$ & 8805 & 42 & $8070 \pm 170$ \\
\hline hcp-Fe-Si9 & 9285 & 59 & $8620 \pm 160$ \\
\hline hcp-Fe-Si9 & 9665 & 79 & $8930 \pm 220$ \\
\hline hcp-Fe-Si9 & 10350 & 117 & $9620 \pm 410$ \\
\hline hcp-Fe-Si9 & 10755 & 144 & $10100 \pm 300$ \\
\hline
\end{tabular}

